\title{
Four Years of Daily Photon Emissions That Have Predicted Major Earthquakes: Raw Data, Spectral Power Density Analyses and Implications for the Geosciences
}

\author{
Michael A. Persinger, Brendan Lehman, Blake T. Dotta, Ghislaine F. Lafreniere \\ Laurentian University, Sudbury, Canada \\ Email: mpersinger@laurentian.ca
}

Received 15 February 2015; accepted 27 March 2015; published 31 March 2015

Copyright (C) 2015 by authors and Scientific Research Publishing Inc.

This work is licensed under the Creative Commons Attribution International License (CC BY).

http://creativecommons.org/licenses/by/4.0/

(c) () Op Open Access

\begin{abstract}
The daily median ground surface flux densities per day from a continuously operating photomultiplier tube unit for four years in Sudbury, Ontario are presented for December 2010 to December 2014. Increases of about 2 to 4 PMT units $\left(1 \mathrm{unit}=5 \times 10^{-11} \mathrm{~W} \cdot \mathrm{m}^{-2}\right)$ for median daily measures reliably occurred about two weeks before $M \geq 7.7$ earthquakes anywhere on the planet. The PMT units, until June 2014, usually returned to baseline within a few days after the events. There has been a slow positive drift in flux power density since about 2012 and a conspicuous maintained increase after May, 2014. The equivalent energy per day if it were represented isotropically within the volume occupied by the earth is the same order of magnitude as the average daily global total seismic energy release. Spectral power densities revealed enhanced peaks (periodicities) between 100 to 150 days, 60 days, 30 days, and 25 days. Discriminable peaks in power were noted around 18 days, 14 days, and 4 to 6 days. These results suggest that continuous measurement of photon emissions within hyper-dark conditions may reveal geophysical processes that precede larger seismic events and could reflect the movement of the earth-solar system around the galactic center.
\end{abstract}

\section{Keywords}

Background Photon Emissions, Global Seismicity, Spectral Power Densities, Daily Measurements

\section{Introduction}

Within the last century a large number of different indicators have been employed to predict the likelihood of

How to cite this paper: Persinger, M.A., Lehman, B., Dotta, B.T. and Lafreniere, G.F. (2015) Four Years of Daily Photon Emissions That Have Predicted Major Earthquakes: Raw Data, Spectral Power Density Analyses and Implications for the Geosciences. International Journal of Geosciences, 6, 311-316. http://dx.doi.org/10.4236/ijg.2015.64024 
seismic events within local and global space [1] [2]. They have been summarized by many researchers and include variables such as alterations in ground water, transient luminous displays, and a variety of piezoelectric phenomena [3]-[6]. These transient luminosities have been reported several hundreds of kilometers form the imminent epicenter [2]. The local occurrence and transient duration of these phenomena often elude contemporary methods of measurement. In addition the relationship often requires substantial statistical analyses to be discernible.

About four years ago we began measuring background photon emissions within the visible wavelengths by photomultiplier tubes over ground rock [7]. The photon emissions in $\mathrm{W} \cdot \mathrm{m}^{-2}$ were measured once per minute for 24 hours per day every day. We have daily mean and median values calculated from those 1440 values. Calibrated measurements indicated that when we began the project the average background was about $10^{-11} \mathrm{~W} \cdot \mathrm{m}^{-2}$. The equipment had been set such that 50 units on a 1 to 100 unit scale was $5 \times 10^{-12} \mathrm{~W} \cdot \mathrm{m}^{-2}$. However for about two weeks before the $8.8 \mathrm{M}$ earthquake in Chile and the $9.0 \mathrm{M}$ earthquake in Japan, the background values increased to 100 to 120 units and remained elevated until a day or two before the seismic events. These profiles have been published previously [7].

Since that time we have noted that very large earthquakes, particularly those $\geq 7.7 \mathrm{M}$ were preceded by conspicuous elevations in median daily PMT values for several days before the event. In addition there have been changes in the background levels of radiant photon power density that are persistent over periods of months. This may suggest recondite alterations in the mechanisms that produce these photons. Here we present for the first time the results of our total data set (4 years) of daily PMT measurements from the Sudbury Station. Spectral analyses of these daily fluctuations have revealed unexpected peaks in power periodicity.

\section{Methods and Materials}

The recording equipment has been a RCA electron tube or photomultiplier tube (PMT) with no filters housed in a BCA IP21 unit. The aperture is $12.56 \mathrm{~cm}^{2}$. It has been kept within a black (painted) wooden box covered with $10 \mathrm{~cm}$ of several layers of black terry cloth towels in a windowless room within the basement of a classroom building. The output from the PMT was transformed to $\mathrm{mV}$ by a millivolt meter for a Model 15 Photometer from SRI Instruments (Pacific Photometric Instruments). The output from the PMT through the photometer was recorded once per minute but visualized continuously by an IBM Thinkpad laptop operated by Windows 95. Both the photometer and laptop were maintained in a separate room than the PMT sensor.

The sensitivity for the photometer was set at 1500 with an input current of 0.01 ( $\max =0.001)$. This allowed the background measurements to oscillate around the midpoint (50) of the meter (1 to 100 units). Calibration by three separate methods indicated that for every 1 unit increase (from 50 units) the equivalent change in radiant power density was $5 \times 10^{-11} \mathrm{~W} \cdot \mathrm{m}^{-2}$ [7]. Measurements were programmed to record the ambient value once per minute. The 1440 measurements per day were downloaded into separate files. The median and mean values per day for the meter units were calculated.

The total continuous data base reported in this paper was between 1 December 2010 and 4 December 2014. There were only two days of missing data due to power failures. To complete spectral analyses the two missing days were replaced by the average of the previous and subsequent day. "Spectra" from SPSS 16 software was employed to complete the spectral analyses to reveal intrinsic periodicities of power densities. Before the two earthquakes during this period $(M=9.0,10$ March, 2011 near Japan and $M=7.7,17$ November, 2013 in the Scotia Sea near Antarctica), the PMT values exceeded the 100 unit scale such that the amplifier was reduced by one increment. For these data the values were transformed by the appropriate multiplier. Hence some PMT values were over 100 . We have found that discriminable increases in daily units of flux density reliably increase before earthquakes somewhere on the planet whose magnitudes are $\geq 7.7$ according to USGS data. Consequently we carefully assessed changes in the daily PMT values before, during and after these events.

\section{Results}

The daily values for the median photon flux densities for the four years between December 2010 and December 2014 are shown in Figure 1.

During this period there were $15 \geq$ M 7.7 seismic events. The first elevation (day 101) reflects the 10 March, 2011 Japanese $M=9.0$ event that produced the destructive tsunami. An increase of 31 units in daily PMT values began 22 February and fluctuated around this value until the March $M=9.0$ event. The oscillations dampened 


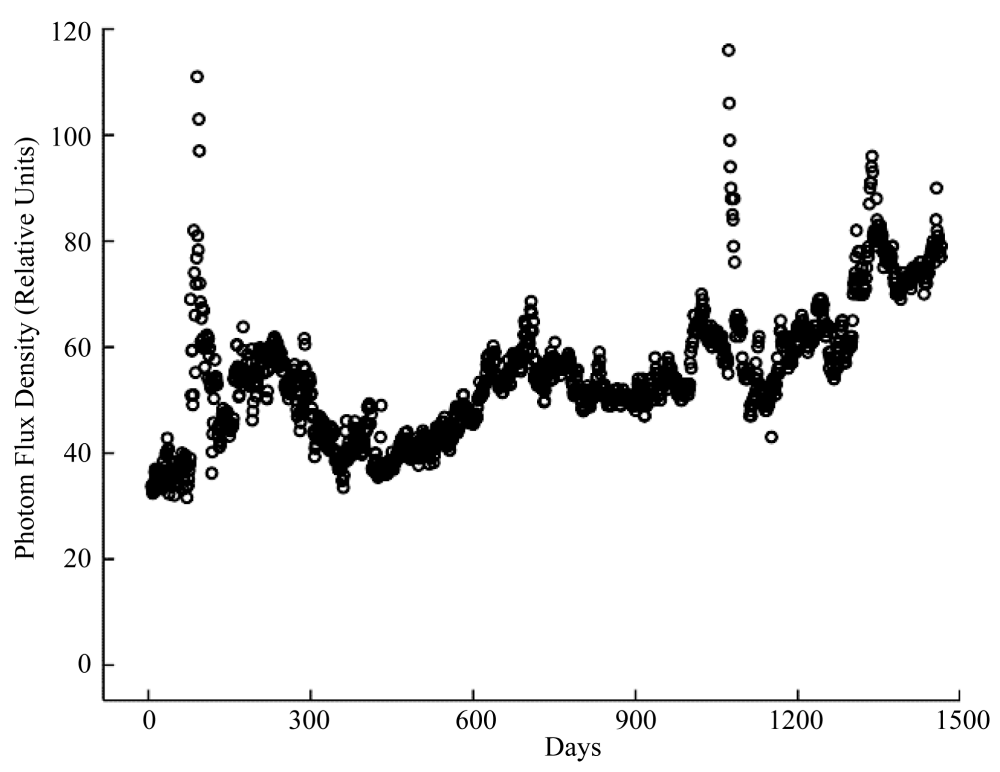

Figure 1. Median value for daily one minute units $\left(50=5 \times 10^{-11} \mathrm{~W} \cdot \mathrm{m}^{-2}\right)$ from the photomultiplier unit housed in hyper-dark conditions as a function of days from 1 December 2010 to 4 December 2014.

until the pre-event baseline was reached around 24 March. The subsequent maintained peak around day 200 was not associated with any single criterion event but there were $9, \mathrm{M} \geq 7.0$ but $<7.7$ events, primarily in the South Pacific.

Close inspection of the data indicated that the $\mathrm{M}=8.6$ and $\mathrm{M}=8.2,11$ April, 2012 events (Sumatra) on day 498 were preceded by an increase of 2 to 4 PMT units per day starting 1 April until the return to baseline on 12 April. Two weeks (31 July) before the 14 August $M=7.7$ event in Russia on day 623, there was a $2-4$ PMT unit increase that returned to baseline the day after the quake. Before the $M=7.7$ event in the Queen Charlotte Islands in Canada on day 698 (28 October, 2012), the PMT measures increased by 5 - 6 units on 23 October but did not return to baseline until 11 November.

Similar patterns were noted during 2013. Approximately 14 days (23 January) before the 6 February $\mathrm{M}=8.0$ event in the Solomon Islands (day 804), the PMT increased by 3 - 4 units and had returned to baseline by 10 February. Eleven days (5 April) before the 16 April $\mathrm{M}=7.7$ event (day 868) there was an increase of 2 units; the values returned to baseline by 20 April. The $M=8.3$ event in Russia on 24 May (day 906) was preceded on 21 May by 1 - 2 units increases that subsided by 26 May. The M = 7.7 event in Pakistan on day 1029 (24 September) was preceded by a shift of +10 units from 30 August to 7 September followed by a decrease by 4 units on 23 September; baseline levels did not return until 6 October. The most anomalous measurement occurred before the $\mathrm{M}=7.7$ event on 17 November 2013 in the Scotia Sea near Antarctica. Between 5 and 6 November the PMT units increased by 56 units. Although during subsequent days the values decreased the values were still more than 30 units above baseline. The baseline magnitudes did not return until 30 November.

The year 2014 showed the continued increased background levels of photon flux density. Before the $\mathrm{M}=8.2$ event on 1 April and $M=7.7$ event on 3 April near in Chile (days 1218, 1220) the PMT increased by 3 units starting 11 March and then to 7 units by 1 April. The baseline did not return until 5 May. However during the intervening period there were 5, $M>7.0$ but $<7.7$ events in the South Pacific and Mexico. An unusual change occurred after the 23 June $M=7.9$ event in the Aleutian Islands (day 1301). Before the event, starting 22 May, the PMT units increased by 4 - 5 units. Instead of returning to baseline after the 23 June event, the PMT measures remained elevated. Correlation analysis for the PMT measures as a function of days indicated the following coefficients over the years: $\leq 2011: \mathrm{r}=0.03, \leq 2012: \mathrm{r}=0.17, \leq 2013: \mathrm{r}=0.41$, and $\leq 2014$ (i.e., all data): $\mathrm{r}=$ 0.66 .

The primary spectral power densities are shown in Figure 2. The vertical axis, based upon the unit measures (35 to 100+ in Figure 1) revealed periodicities around 100 to 150 days (3 to 5 months) and around 60 days.

Because most of the cases were contained within periodicities of $<50$ days, the power density profiles, although 


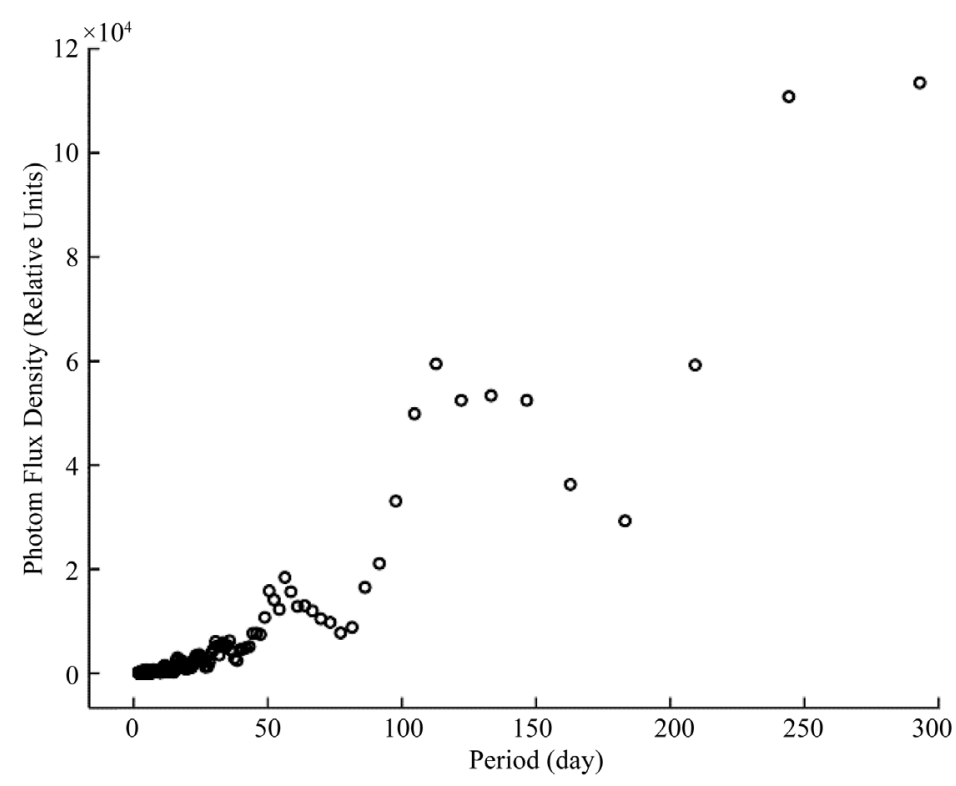

Figure 2. Spectral power density of photon flux density as a function of periodicity (in days) for the 4 years of daily PMT measurements.

the relative amount of energy would be much less, were investigated. These results are shown in Figure 3. In addition to the approximately 30 days and 25 days peak in spectral power there was a distinguishable peak around 18 days, 11 and 14 days.

Still further differentiation for very small amplitude variations was discerned for periodicities of less than 7 days. In addition to the sharp 3 days periodicity there was a broader 4 to 6 days (mean 4.8 days) (Figure 4) peak in power density for the photon emissions we recorded at the station.

\section{Discussion}

The daily median values for flux density for the last four years from our station was not constant but displayed major and minor periodicities that may have relevance for understanding the origin and nature of seismicity. Assuming the measurements were not consequences of instrumental anomalies, the results indicate that the background photon flux densities have gradually increased after the year 2011. Within the last part of 2014, the increase was quite significant.

Despite the drifts over months to years of the median daily PMT values, some consistent patterns emerged. First, for all of the 15, $M \geq 7.7$ seismic events during the four years of measurement there was an average increase of about 2 to 4 units that began within 1 day about two weeks before the events. The return to the initial values usually occurred the day after the event unless there were subsequent seismic events between $M>7.0$ and $<7.7 \mathrm{M}$ somewhere on the planet. This suggests that with the appropriate algorithm relatively accurate predictions could be made with respect to when (but not where) this class of seismic events will occur.

Although from an energetic perspective the marked elevation of PMT units the two weeks before the $M=9.0$, 7.9 and 7.7 events during 10-11 March, 2011 in Japan could be appreciated, the sudden shift of almost 50 units before the Antarctica event of 17 November, 2013 is more difficult to reconcile. It was only M 7.7. If extrapolations from the Japanese event were considered the magnitude of this event should have been much larger. Assuming there is no recondite entanglement between the pre-Cambrian Shield upon which our sensor is located and Antarctica, there may be other potential explanations for this discrepancy assuming the instrumentation was functioning appropriately.

The solar system's velocity around the galactic center is about $240 \mathrm{~km} \cdot \mathrm{s}^{-1}$. The orbit is completed once every approximately 250 million years. This means that the sun-earth system could be moving through different configurations of sub-matter space that could affect the processes associated with photon density. Calculations [8] have indicated that the energy available within the earth as a correlate of this velocity would be in the same order of magnitude as the energy associated with global, daily seismicity. 


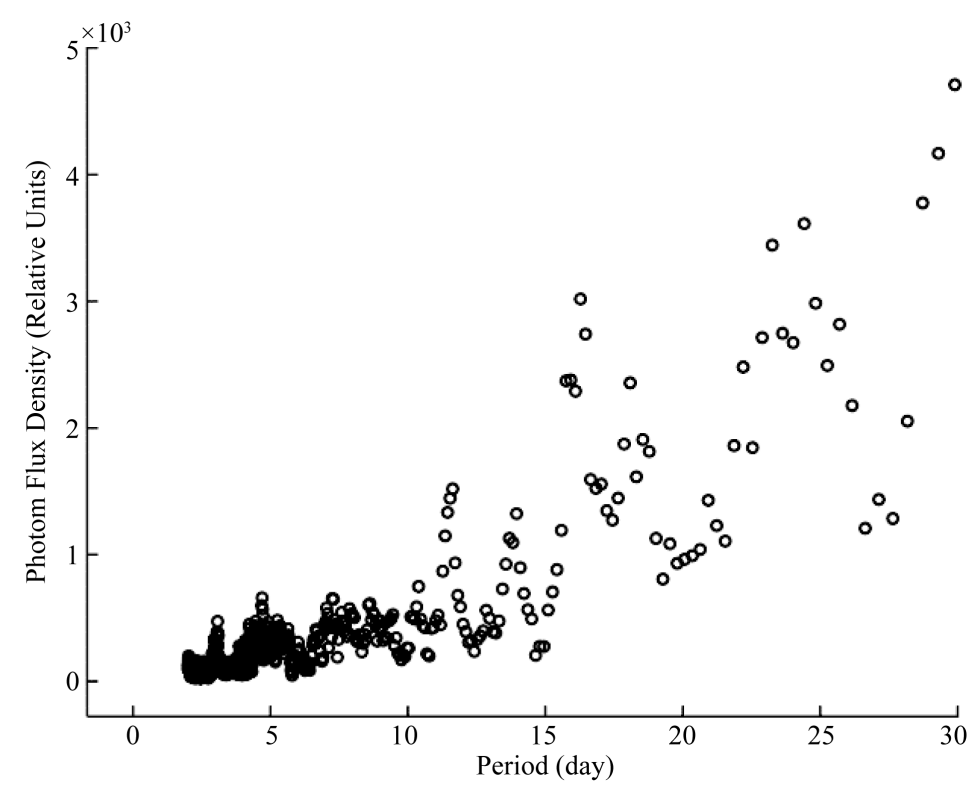

Figure 3. Spectral power density of photon flux density as a function of periodicity (in days) for the 4 years of daily PMT measurements.

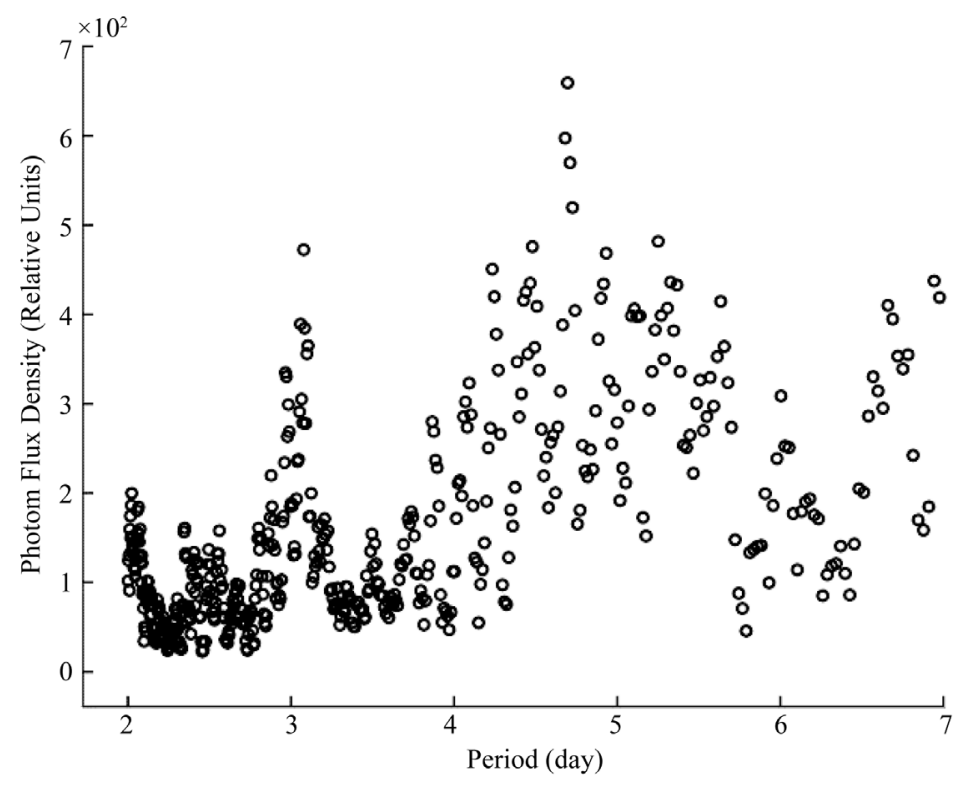

Figure 4. Spectral power density of periodicities less than 7 days to discern recondite frequencies. Note the wide spectrum increased in power density for periodicities between 4 and 6 days and the very fine peak around 3 days.

The baseline of $\sim 5 \times 10^{-11} \mathrm{~W} \cdot \mathrm{m}^{-2}$ for the radiant flux density of photons from our photomultiplier unit in the basement of a four story block and brick building may appear to be a small value. However if this value is assumed to be representative of power density per volume and the volume of the earth $\left(1.29 \times 10^{21} \mathrm{~m}^{3}\right)$ is considered as a unit, the total energy would be $6.45 \times 10^{10} \mathrm{~W}$ or J.s ${ }^{-1}$. The complete rotation of the earth, a day, involves $8.64 \times 10^{4} \mathrm{~s}$. Hence the total energy per day from photon emissions, if indeed the measure reflects some aspect of earth space, would $5.57 \times 10^{15} \mathrm{~J}$ per day. According to global seismic data and calculation for global total energy release per day as all seismic events [8] the average total earthquake energy for the years 2011 through 2013 was $3.2 \times 10^{15} \mathrm{~J}$. This is within measurement error of the equivalent in energy released as photons. 
As a general verification of this relationship Spearman and Pearson correlations were conducted for the average total seismic energy release per month from the planet and the average PMT measurements for the years 2011, 2012 and 2013 (we did not have the complete seismic data for 2014). There were no statistically significant correlations. The absence of a significant correlation between monthly averages of photon flux density and total global seismic energy does not necessarily negate their relationship. We suggest that the background photon density is equivalent to the intercept in a linear regression. For example if the range of variations in some measure was 500 to 600 and some second variable was correlated 0.9 (for example) with the this variation, then this powerful association would still be superimposed upon the "stable" baseline of 500. If this analogy were applicable here, then there is a second mechanism or process that mediates the relationship between the daily photon flux and the occurrence of total seismic energy.

\section{Acknowledgements}

The authors thank Dr. John S. Derr and Professor David A. E. Vares for their suggestions and technical contributions.

\section{References}

[1] Rikitake, T. (1976) Earthquake Prediction. Elsevier, Amsterdam.

[2] Persinger, M.A. and Derr, J.S. (2013) Luminous Shapes with Unusual Motions as Potential Predictors of Earthquakes: A Historical Summary of the Validity and Application of the Tectonic Strain Theory. International Journal of Geosciences, 4, 387-396. http://dx.doi.org/10.4236/ijg.2013.42037

[3] Milne, J. (1911) Earthquakes and Luminous Phenomena. Nature, 87, 16. http://dx.doi.org/10.1038/087016a0

[4] Derr, J.S. (1986) Luminous Phenomena and Their Relationship to Rock Fracture. Nature, 321, 470-471. http://dx.doi.org/10.1038/321470a0

[5] Chen, Q. and Nur, A. (1992) Pore Fluid Pressure Effects in Anistropic Rocks: Mechanisms for Induced Seismicity and Weak Faults. Pageoph, 139, 463-469. http://dx.doi.org/10.1007/BF00879947

[6] Constain, J.K., Bolinger, G.A. and Speer, J.A. (1987) Hydroseismicity: A Hypothesis for the Role of Water in the Generation of Intraplate Seismicity. Seismological Research Letters, 58, 41-60.

[7] Persinger, M.A., Lafreniere, G.F. and Dotta, B.T. (2013) Marked Increases in Background Photon Emissions in Sudbury Ontario More Than One Week before the Magnitude > 8.0 Earthquakes in Japan and Chile. International Journal of Geosciences, 3, 627-629. http://dx.doi.org/10.4236/ijg.2012.33062

[8] Persinger, M.A. (2014) Conversion Energy from Movement of the Solar System through Universal Pressure: Reflections in Seismic Events and Global Temperatures. International Letters of Chemistry, Physics and Astronomy, 17, 78-86. 